(2) Open Access Full Text Article

\title{
Intraocular pressure dynamics with prostaglandin analogs: a clinical application of the water- drinking test
}

This article was published in the following Dove Press journal:

Clinical Ophthalmology

22 July 2016

Number of times this article has been viewed

\author{
Pelin Özyol' \\ Erhan Özyol' \\ Ercan Baldemir ${ }^{2}$ \\ 'Ophthalmology Department, \\ ${ }^{2}$ Biostatistics Department, Faculty \\ of Medicine, Mugla Sitki Kocman \\ University, Mugla, Turkey
}

Correspondence: Pelin Ozyol Muğla Sıtkı Koçman Üniversitesi Eğitim ve Araștırma Hastanesi Göz Hastalıkları Kliniği, 48000, Menteșe, Mugla, Turkey Tel +905063976465

Email pelingesoglu@yahoo.com.tr
Aim: To evaluate the clinical applicability of the water-drinking test in treatment-naive primary open-angle glaucoma patients.

Methods: Twenty newly diagnosed primary open-angle glaucoma patients and 20 healthy controls were enrolled in this prospective study. The water-drinking test was performed at baseline and 6 weeks and 3 months after prostaglandin analog treatment. Peak and fluctuation of intraocular pressure (IOP) measurements obtained with the water-drinking test during follow-up were analyzed. Analysis of variance for repeated measures and paired and unpaired $t$-tests were used for statistical analysis.

Results: The mean baseline IOP values in patients with primary open-angle glaucoma were $25.1 \pm 4.6 \mathrm{mmHg}$ before prostaglandin analog treatment, $19.8 \pm 3.7 \mathrm{mmHg}$ at week 6 , and $17.9 \pm 2.2 \mathrm{mmHg}$ at month 3 after treatment. The difference in mean baseline IOP of the waterdrinking tests was statistically significant $(P<0.001)$. At 6 weeks of prostaglandin analog treatment, two patients had high peak and fluctuation of IOP measurements despite a reduction in baseline IOP. After modifying treatment, patients had lower peak and fluctuation of IOP values at month 3 of the study.

Conclusion: Peak and fluctuation of IOP in response to the water-drinking test were lower with prostaglandin analogs compared with before medication. The water-drinking test can represent an additional benefit in the management of glaucoma patients, especially by detecting higher peak and fluctuation of IOP values despite a reduced mean IOP. Therefore, it could be helpful as a supplementary method in monitoring IOP in the clinical practice.

Keywords: glaucoma, intraocular pressure, water-drinking test, prostaglandin analog, intraocular pressure fluctuation

\section{Introduction}

The main goal of treatment in patients with glaucoma is preservation of visual function. The lowering of intraocular pressure (IOP) is the only therapy that shows evidence of preservation of the visual field. ${ }^{1,2}$ Monotherapy remains the preferred first treatment approach for newly diagnosed patients. ${ }^{3}$ Latanoprost, travoprost, and bimatoprost are the most frequently used prostaglandin analogs for monotherapy owing to their powerful IOP-decreasing effects by facilitating outflow of aqueous humor. Tafluprost, a preservative-free prostaglandin medication, has also a proven preclinical and clinical IOP-lowering efficacy. ${ }^{4,5}$

Brubaker ${ }^{6,7}$ suggested that the water-drinking test could be used as an indirect measurement method of outflow facility to compare IOP responses of glaucomatous eyes to different drugs. The ability of the eye to recover from a transient rise of IOP 
following water ingestion depends on the outflow facility. ${ }^{7} \mathrm{~A}$ treatment that improves the outflow facility could affect IOP alterations measured with the water-drinking test. Herein, we aimed to observe clinical applicability of the water-drinking test in treatment-naive primary open-angle glaucoma (POAG) patients before and after prostaglandin analog treatment for treatment strategy during follow-up period.

\section{Materials and methods}

This prospective study included 20 patients who were newly diagnosed with POAG and 20 healthy subjects for control group. This study was conducted in accordance with the tenets of Declaration of Helsinki. All patients signed an informed consent agreement and the study was approved by the ethics committee of Mugla University before any procedure was performed.

All qualified subjects underwent a comprehensive ophthalmological evaluation, including visual acuity testing, slit lamp biomicroscopy, gonioscopy, indirect ophthalmoscopy with a +78 D lens, IOP measurement with a calibrated Goldmann applanation tonometer, central corneal thickness measurement, and visual field testing. POAG was defined as IOP level $>21 \mathrm{mmHg}$, with the presence of glaucomatous optic neuropathy, abnormal 24-2 SITA-standard visual field examinations (Humphrey Visual Field Analyzer II 740; Carl Zeiss Meditec AG, Jena, Germany), and open angles during gonioscopy. Glaucomatous optic neuropathy was defined using the following criteria: focal or diffuse neuroretinal rim thinning, focal or diffuse retinal nerve fiber layer loss, or an intereye vertical cup-to-disk ratio asymmetry $>0.2$, not explained by differences in disk size. Abnormal visual field tests were defined by the presence of a cluster of three or more nonedge points that had sensitivities with $P<0.05$ and one of the points presenting sensitivity with $P<0.01$ or pattern standard deviation value with $P<0.05$ or glaucoma hemifield test outside normal limits. Visual field testing was performed again at 6 months of the study. Visual field test results had to be reliable based on false-positive rates $\leq 25 \%$, false-negative rates $\leq 25 \%$, and fixation losses $\leq 33 \%$.

Ocular exclusion criteria for the study were any previous treatment for glaucoma; closed or barely open anterior chamber angle; history of acute angle closure, previous incisional ocular surgery, and laser trabeculoplasty; any other ocular disease that could affect the visual fields or that could lead to increased IOP; and contraindication to any study medication. Patients with a history of cardiac or renal disease were also excluded.

Water-drinking tests were performed at the same time of the day by the same investigator and using the same calibrated Goldmann applanation tonometer. For the repeated water-drinking test, the investigator was masked to the results of the previous tests.

At the baseline, the water-drinking test was performed. After that, the prostaglandin analog treatment was initiated to POAG patients. The water-drinking test was repeated at 6 weeks and 3 months of the study after prostaglandin analog treatment. To evaluate whether the prostaglandin analogs provide sufficient IOP decrease, at least 20\%-25\% decrease in baseline IOP was required. If the patient had $<20 \%$ IOP decrease, the case would be considered as nonresponder patient or nonadherence to treatment. The water-drinking test was also performed in the control group at baseline and 3 months of the study.

The water-drinking test was performed as follows. Patients were asked not to ingest fluid 2 hours prior to the water-drinking test. The IOP was measured before the ingestion of water (baseline IOP) and after drinking $1 \mathrm{~L}$ of water in $<5$ minutes. IOP was measured 15 minutes, 30 minutes, 45 minutes, and 60 minutes after water ingestion. The average of three measurements with Goldmann applanation tonometry was recorded at each time point. All measurements were performed between $2 \mathrm{pm}$ and $4 \mathrm{pm}$.

IOP peak was defined as the highest IOP of the 15 minutes, 30 minutes, 45 minutes, and 60 minutes measurements obtained during each test. IOP fluctuation was defined as the difference between the peak IOP and the baseline measurement taken before patients began drinking water. Mean IOP was obtained from the mean of the 15 minutes, 30 minutes, 45 minutes, and 60 minutes measurements after water consumption. The eye with higher IOP of each patient was included in this study. If both eyes have similar IOP, right eye was selected for statistical analysis.

\section{Statistical analysis}

The Kolmogorov-Smirnov test was used for confirming the normality of assumption. Data were reported as mean \pm standard deviation. Paired $t$-test was used when comparing POAG patients and controls. A one-way repeated-measures analysis of variance was conducted to determine whether there were significant differences in the IOP measurements obtained from the water-drinking test at the baseline, week 6 , and month 3 . A post hoc test was performed using the Bonferroni correction to determine a significant difference between any two visits. The visual field test indices of POAG patients and the water-drinking test data of control group were analyzed using paired $t$-test. A $P$-value $<0.05$ was considered as statistically significant. The study has $80 \%$ power to detect a difference of $1.0 \mathrm{mmHg}$ between the measurements assuming an $\mathrm{SD}$ of $1.0 \mathrm{mmHg}$ and an $\alpha$-level of 0.05 with 20 eyes per group. 


\section{Results}

Twenty eyes of POAG patients and 20 eyes of control group were evaluated. The demographic and clinical characteristics of patients are presented in Table 1. Before prostaglandin analog treatment, the mean of baseline IOP in the POAG group was $25.1 \pm 4.6 \mathrm{mmHg}$. Latanoprost (six patients), travoprost (seven patients), and bimatoprost (seven patients) were administered to POAG patients. The mean baseline IOP was $19.8 \pm 3.7 \mathrm{mmHg}$ at week 6 , and it was $17.9 \pm 2.2 \mathrm{mmHg}$ at month 3 . The difference in mean baseline IOP of the water-drinking tests was statistically significant $(P<0.001)$. At 6 weeks of prostaglandin analog treatment, two patients had high IOP peak values and IOP fluctuation measurements, although they had an average of $22 \%$ baseline IOP reduction (baseline vs week 6: patient 1 [under latanoprost treatment]; peak IOP $30 \mathrm{mmHg}$ vs $24.5 \mathrm{mmHg}$ and IOP fluctuation $5.0 \mathrm{mmHg}$ vs $5.0 \mathrm{mmHg}$, patient 2 [under travoprost treatment]; peak IOP $31 \mathrm{mmHg}$ vs $25 \mathrm{mmHg}$ and IOP fluctuation $4.5 \mathrm{mmHg}$ vs $4.0 \mathrm{mmHg}$ ). Fixed prostaglandin/beta blocker combination was initiated to two patients. Patients had lower IOP peak and IOP fluctuation values at 3 months of the study (patient 1: $22.0 \mathrm{mmHg} / 3.5 \mathrm{mmHg}$ and patient 2 : $20.5 \mathrm{mmHg} / 2.5 \mathrm{mmHg}$; IOP peak and IOP fluctuation values, respectively). At 3 months of the study, in POAG patients, the decrease in mean baseline IOP was $7.2 \pm 3.4$ in $\mathrm{mmHg}$ and $28 \%$ in percentage. The mean IOP values of the water-drinking test in POAG patients and controls at visits are shown in Figure 1.

Table 2 presents IOP peak and IOP fluctuation values at visits in both POAG patients and controls. In POAG patients, the decrease in IOP peak and IOP fluctuation was statistically significant $(P<0.001$ and $P=0.003$, respectively).

No significant difference was observed in visual field test indices between baseline and month 6 (mean deviation: $4.25 \pm 2.32$ vs $4.17 \pm 2.95, P=0.10$ and pattern standard deviation: $3.31 \pm 2.53$ vs $3.36 \pm 2.58, P=0.12$ ).

Intracorrelation test was carried out to compare the testretest variability of control patients. The intraclass coefficients

Table I Demographic and clinical data of the patients

\begin{tabular}{|c|c|c|c|}
\hline & $\begin{array}{l}\text { POAG patients } \\
(n=20)\end{array}$ & $\begin{array}{l}\text { Control patients } \\
(n=20)\end{array}$ & $P$-value ${ }^{a}$ \\
\hline Age (years) & $54.5 \pm 7.28$ & $51.2 \pm 9.81$ & 0.36 \\
\hline Female/male & $9 / 6$ & $10 / 7$ & 0.45 \\
\hline ССТ $(\mu \mathrm{m})$ & $551.3 \pm 22.1$ & $548.8 \pm 18$ & 0.14 \\
\hline Initial IOP $(\mathrm{mmHg})$ & $25.1 \pm 4.6$ & $14.9 \pm 2.3$ & $<0.001$ \\
\hline
\end{tabular}

Notes: anpaired $t$-test. Data presented as mean $\pm S D$, number, or $P$-value. Abbreviations: CCT, central corneal thickness; IOP, intraocular pressure; POAG, primary open-angle glaucoma.

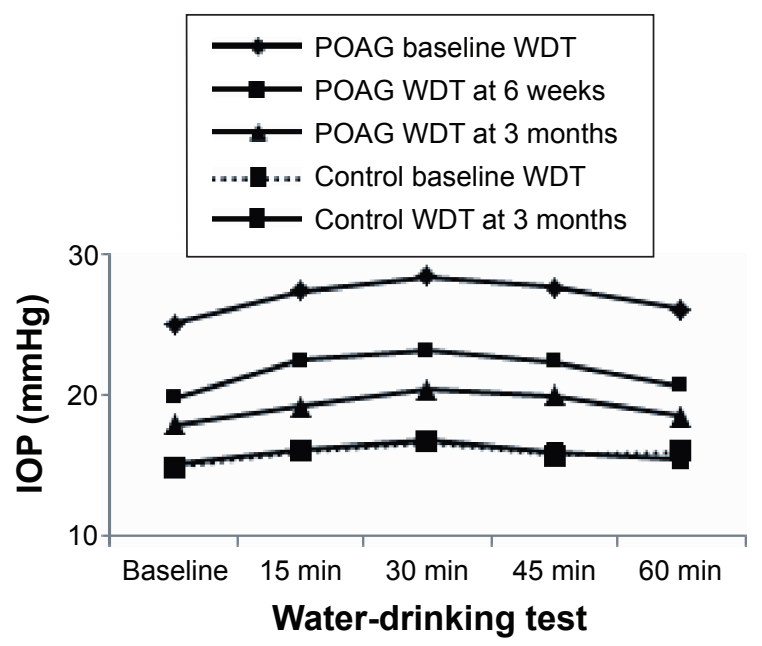

Figure I Mean IOP values of the water-drinking test in POAG patients and controls.

Abbreviations: IOP, intraocular pressure; min, minutes; POAG, primary openangle glaucoma; WDT, water-drinking test.

for the two water-drinking tests in control patients were 0.89 for IOP peak and 0.62 for IOP fluctuation $(P<0.001)$.

\section{Discussion}

Previous studies have indicated the importance of reduction in IOP for preventing the progression of glaucomatous damage. ${ }^{2,8}$ However, not only mean IOP but also peaks and diurnal variation of IOP have been shown as risk factors for glaucomatous progression. ${ }^{8-11}$ Studies have shown that the IOP peak levels of the water-drinking test strongly correlate with the peak of shortened diurnal tension curves and longterm IOP measurements. ${ }^{12,13}$ Additionally, the change in IOP during the water-drinking test has been reported as a risk factor for visual field loss. ${ }^{14,15}$ Therefore, the water-drinking test may be used as a determinative test for detecting patients whose IOP spikes could not be observed during office hours and who could have a risk for visual field progression. The water-drinking test has been used to assess the effectiveness of treatments including medications and filtering surgery as well as monitoring IOP peaks. In our study, we evaluated the clinical applicability of the water-drinking test in the management of treatment-naive POAG patients. The study was conducted on POAG patients treated with only prostaglandin analogs for providing treatment homogeneity and studying a glaucoma medication enhancing outflow. Ninety percent of patients had lower IOP peak and IOP fluctuation values as well as lower baseline IOP measurements with the water-drinking test after prostaglandin analog medication, whereas $10 \%$ of patients had high IOP peak and IOP fluctuation measurements despite lower mean baseline IOP values. Lower IOP peak and IOP fluctuation measurements were 
Table 2 Mean IOP peak and IOP fluctuation values at visits in POAG patients and controls

\begin{tabular}{|c|c|c|c|c|c|c|c|}
\hline & \multicolumn{4}{|l|}{ POAG } & \multicolumn{3}{|l|}{ Control } \\
\hline & Baseline & Week 6 & Month 3 & $P$-value ${ }^{a}$ & Baseline & Month 3 & $P$-value ${ }^{b}$ \\
\hline Peak IOP & $28.2 \pm 5.3$ & $19.5 \pm 4.2$ & $17.2 \pm 3.9$ & $<0.001$ & $16.8 \pm 3.2$ & $16.6 \pm 3.5$ & $>0.05$ \\
\hline IOP fluctuation & $4.7 \pm 1.4$ & $2.8 \pm 0.9$ & $2.4 \pm 1.0$ & 0.0032 & $2.2 \pm I .1$ & $2.0 \pm 0.8$ & $>0.05$ \\
\hline
\end{tabular}

Notes: aNOVA for repeated measures; ${ }^{\text {b}}$ paired $t$-test. Data presented as mean \pm SD or $P$-value.

Abbreviations: ANOVA, analysis of variance; IOP, intraocular pressure; POAG, primary open-angle glaucoma.

provided with the water-drinking test at month 3 after a fixed prostaglandin/beta blocker combination was initiated. This clinical experience indicates that treatment strategy could be managed according to IOP measurements in response to the water-drinking test despite a reduced mean IOP.

The mechanism of IOP increase after water ingestion remains unclear. Many mechanisms such as plasma hypoosmolarity-induced aqueous ultrafiltration, autonomic nervous system stimulation, increased episcleral venous pressure, and choroidal expansion have been proposed. ${ }^{16-20}$ However, choroidal expansion mechanism seems to be more effective in angle closure eyes than in open-angle eyes or healthy eyes and this was quantified with optical coherence tomography studies. . $^{21,22}$

Several studies have reported an increase in the facility of outflow after treatment with prostaglandin analogs. ${ }^{23,24}$ In our study, we found that patients on treatment with prostaglandin analogs had significantly less IOP peak and IOP fluctuation values compared to before treatment in response to the waterdrinking test, that represents outflow facility indirectly. This finding also indicates an improvement in the outflow facility in patients under prostaglandin analogs treatment. If outflow facility is enhanced, the eye can cope with an increase in volume easily, so that the IOP peak and IOP fluctuation in response to the water-drinking test could be less. In a stress condition, to test the effect of IOP lowering medications on the ability to maintain IOP, Vetrugno et $\mathrm{al}^{24}$ performed the water-drinking test in POAG patients under topical glaucoma treatment. The authors concluded that topical medications that enhance outflow may provide better IOP stabilization than medications that decrease aqueous humor inflow.

The IOP values in response to the water-drinking test can vary even with different prostaglandin analogs because of different effects on outflow facility. We did not compare the water-drinking test response in patients treated with different prostaglandin analog subtypes because of small sample size. Susanna et a ${ }^{25}$ compared the IOP fluctuations using the water-drinking test in POAG patients being treated with latanoprost and unoprostone. The authors reported that patients under treatment with latanoprost had significantly less IOP fluctuations in response to the water-drinking test, compared to patients using unoprostone. In another study, it was reported that bimatoprost provided the lowest increase in IOP and the fastest recovery to baseline values with the water-drinking test compared with latanoprost and travoprost. The authors concluded that this result depends on dual mechanism of bimatoprost, both by enhancing the pressure-sensitive (trabecular) outflow and by increasing the pressure-insensitive (uveoscleral) pathways. ${ }^{24}$

Previous studies have suggested the importance of the water-drinking test to determine a risk factor for the development of glaucomatous visual field defect. ${ }^{14,15,26,27}$ Armaly et al reported that pressure change after water drinking as one of five potential risk factors was associated with the development of glaucomatous visual field defects in patients with open-angle glaucoma. ${ }^{15}$ Besides, it was reported that in patients with progressive visual field loss, the IOP peak levels were significantly greater than the levels observed in nonprogressive group. ${ }^{15,26}$ Similarly, it was reported that eyes with worse glaucomatous lesion presented higher IOP fluctuations than the contralateral eyes, even when equally treated with topical medication. ${ }^{27}$ No significant difference was found in visual field indices at 6 months of this study. In order to evaluate visual field progression, our study has a short follow-up period. The water-drinking test may be mainly useful in the case of visual field progression in apparently controlled patients. Therefore, it would be meaningful with long-term studies to detect whether there is a progression in visual field loss especially in cases with high IOP peak and IOP fluctuation measured with the water-drinking test despite low mean IOP.

Recently, reproducibility of the water-drinking test has been evaluated in treated and untreated open-angle glaucoma patients. It has been reported that during the water-drinking test, IOP peaks were highly reproducible, but IOP fluctuation was fairly reproducible. ${ }^{28,29}$ Similarly, in the control group of this study, the IOP peaks presented excellent reproducibility and IOP fluctuation was fairly reproducible with a slightly higher intraclass correlation coefficient value than other studies. This could be due to the difference in the analyzed 
population. Reproducibility of the water-drinking tests in POAG patients was not evaluated due to the change in treatment between the water-drinking tests.

\section{Conclusion}

Our results showed that the IOP peak and IOP fluctuation in response to the water-drinking test were lower with prostaglandin analogs that enhance outflow compared with before medication. The water-drinking test can represent an additional benefit in the management of POAG patients, especially detecting higher IOP peak and IOP fluctuation values despite a reduced mean IOP. Therefore, it could be helpful as a supplementary method in monitoring IOP in clinical practice.

\section{Disclosure}

None of the authors have a financial or proprietary interest in any material or method mentioned, and there was no public or private support. The authors report no conflicts of interest in this work.

\section{References}

1. Collaborative Normal-Tension Glaucoma Study Group. The effectiveness of intraocular pressure reduction in the treatment of normal-tension glaucoma. Am J Ophthalmol. 1998;126:498-505.

2. The AGIS Investigators. The Advanced Glaucoma Intervention Study (AGIS): 7. The relationship between control of intraocular pressure and visual field deterioration. Am J Ophthalmol. 2000;130:429-440.

3. Alward WLM. Medical management of glaucoma. N Engl J Med. 1998; 339:1298-1307.

4. Sutton A, Gilvarry A, Ropo A. A comparative placebo-controlled study of prostanoid fluoroprostaglandin receptor agonist tafluprost and latanoprost in healthy males. J Ocul Pharmacol Ther. 2007;23:359-365.

5. Uusitalo H, Pillunat LE, Ropo A. Efficacy and safety of tafluprost $(0.0015 \%)$ versus latanoprost $(0.005 \%)$ eye drops in open-angle glaucoma and ocular hypertension: 24-month results of a randomized, double-masked phase III study. Acta Ophthalmol. 2010; 88:12-19.

6. Brubaker RF. Importance of outflow facility. Int Glaucoma Rev. 2001; 3(1):5.

7. Brubaker RF. Targeting outflow facility in glaucoma management. Surv Ophthalmol. 2003;48:17-20.

8. Leske MC, Heijl A, Hussein M, Bengtsson B, Hyman L, Komaroff E. Early Manifest Glaucoma Trial Group. Factors for glaucoma progression and the effect of treatment: the early manifest glaucoma trial. Arch Ophthalmol. 2003;121:48-56.

9. Chauhan BC, Drance SM. The relationship between intraocular pressure and visual field progression in glaucoma. Graefes Arch Clin Exp Ophthalmol. 1992;230:521-526.

10. Zeimer RC, Wilensky JT, Gieser DK, Viana MA. Association between intraocular pressure peaks and progression of visual field loss. Ophthalmology. 1991;98:64-69.
11. Asrani S, Zeimer R, Wilensky J, Gieser D, Vitale S, Lindenmuth K. Large diurnal fluctuations in intraocular pressure are an independent risk factor in patients with glaucoma. J Glaucoma. 2000;9:134-142.

12. De Moraes CG, Furlanetto RL, Reis AS, Vegini F, Cavalcanti NF, Susanna R Jr. Agreement between stress intraocular pressure and long-term intraocular pressure measurements in primary open angle glaucoma. Clin Experiment Ophthalmol. 2009;37:270-274.

13. Kumar RS, de Guzman MH, Ong PY, Goldberg I. Does peak intraocular pressure measured by water drinking test reflect peak circadian levels? A pilot study. Clin Experiment Ophthalmol. 2008;36:312-315.

14. Yoshikawa K, Inohue T, Inohue Y. Normal tension glaucoma: the value of predictive tests. Acta Ophthalmol. 1993;71:463-470.

15. Armaly MF, Krueger DE, Maunder L, et al. Biostatistical analysis of the Collaborative Glaucoma Study I. Summary report of the risk factors for glaucomatous visual-field defects. Arch Ophthalmol. 1980; 98:2163-2171.

16. Chen CH, Lu DW, Chang CJ, Chiang CH, Chou PI. The application of water drinking test on the evaluation of trabeculectomy patency. J Ocul Pharmacol Ther. 2000;16:37-42.

17. Danesh-Meyer HV. The water drinking test: the elegance of simplicity. Clin Experiment Ophthalmol. 2008;36:301-303.

18. De Moraes CG, Reis AS, Cavalcante AF, Sano ME, Susanna R Jr. Choroidal expansion during the water drinking test. Graefes Arch Clin Exp Ophthalmol. 2009;247:385-389.

19. Goldberg I, Clement CI. The water drinking test. Am J Ophthalmol. 2010;150:447-449.

20. Kerr NM, Danesh-Meyer HV. Understanding the mechanism of the water drinking test: the role of fluid challenge volume in patients with medically controlled primary open angle glaucoma. Clin Experiment Ophthalmol. 2010;38:4-9.

21. Arora KS, Jefferys JL, Maul EA, Quigley HA. Choroidal thickness change after water drinking is greater in angle closure than in open angle eyes. Invest Ophthalmol Vis Sci. 2012;21(53):6393-6402.

22. Kocabeyoğlu S, Uzun S, Kadayıfçılar S, Mocam MC, Irkec M. The relationship between choroidal expansion and intraocular pressure raise during the water drinking test in healthy subjects and exfoliation syndrome. J Glaucoma. 2016;25:324-328.

23. Lim KS, Nau CB, O’Byrne MM, et al. Mechanism of action of bimatoprost, latanoprost, and travoprost in healthy subjects. A crossover study. Ophthalmology. 2008;115:790-795.

24. Vetrugno M, Sisto D, Trabucco T, Balducci F, Delle Noci N, Sborgia C. Water-drinking test in patients with primary open-angle glaucoma while treated with different topical medications. JOcul Pharmacol Ther. 2005; 21:250-257.

25. Susanna R Jr, Medeiros FA, Vessani RM, Giampani J Jr, Borges AS, Jordao ML. Intraocular pressure fluctuations in response to the waterdrinking provocative test in patients using latanoprost versus unoprostone. J Ocul Pharmacol Ther. 2004;20:401-410.

26. Susanna R Jr, Hatanaka M, Vessani RM, Pinheiro A, Morita C. Correlation of asymmetric glaucomatous visual field damage and waterdrinking test response. Invest Ophthalmol Vis Sci. 2006;47:641-644.

27. Susanna R Jr, Vessani RM, Sakata L, Zacarias LC, Hatanaka M. The relation between intraocular pressure peak in the water drinking test and visual field progression in glaucoma. Br J Ophthalmol. 2005;89: 1298-1301.

28. Babic M, De Moraes CG, Hatanaka M, Ju G, Susanna R Jr. Reproducibility of the water drinking test in treated glaucomatous patients. Clin Experiment Ophthalmol. 2015;43:228-233.

29. Hatanaka M, Alencar LM, De Moraes CG, Susanna R Jr. Reproducibility of intraocular pressure peak and fluctuation of the water drinking test. Clin Experiment Ophthalmol. 2013;41:355-359. 


\section{Publish your work in this journal}

Clinical Ophthalmology is an international, peer-reviewed journal covering all subspecialties within ophthalmology. Key topics include: Optometry; Visual science; Pharmacology and drug therapy in eye diseases; Basic Sciences; Primary and Secondary eye care; Patient Safety and Quality of Care Improvements. This journal is indexed on

Submit your manuscript here: http://www.dovepress.com/clinical-ophthalmology-journal
PubMed Central and CAS, and is the official journal of The Society of Clinical Ophthalmology (SCO). The manuscript management system is completely online and includes a very quick and fair peer-review system, which is all easy to use. Visit http://www.dovepress.com/ testimonials.php to read real quotes from published authors. 